\title{
Management of motor neurone disease
}

\section{R S Howard, R W Orrell}

Postgrad Med J 2002;78:736-741

Motor neurone disease is a progressive neurodegenerative disorder leading to severe disability and death. It is clinically characterised by mixed upper and lower motor neurone involvement affecting bulbar, limb, and respiratory musculature. Recent guidelines have established diagnostic criteria and defined management of the condition. In a proportion of familial amyotrophic lateral sclerosis there is a mutation in the gene encoding the enzyme copper/zinc superoxide dismutase 1; this has allowed mutation screening and generated considerable laboratory based research. The diagnosis must be given with care and consideration and close follow up is essential. Management involves a multidisciplinary team based in the hospital and the community. Riluzole is the only drug shown to have a disease modifying effect and has been approved by the National Institute for Clinical Excellence. The essence of care is good symptomatic management, including nutritional support with percutaneous endoscopic gastrostomy and ventilatory care with non-invasive ventilation. Palliative care should be introduced before the terminal stages after careful discussion with the patient and carers. Knowledge of this condition has grown dramatically recently with a parallel improvement in treatment and ability to deal with the most troublesome problems.

See end of article for authors' affiliations

Correspondence to: Dr Robin S Howard Batten/Harris Intensive Care Unit, National Hospital for Neurology and Neurosurgery, Queen Square, London WCIN 3BG, UK robin.howard@talk21.com

Submitted 17 June 2002 Accepted 31 July 2002
M otor neurone disease (MND) is a neurodegenerative disorder characterised by progressive involvement of the corticospinal tract and the motor neurones of the ventral cord and brainstem.

Involvement of the central (upper) motor neurones leads to spasticity, weakness and hyperreflexia, while lower motor neurone impairment will cause fasciculation, atrophy, weakness, and hyporeflexia. Amyotrophic lateral sclerosis is characterised by the involvement of upper and lower limb territories and encompasses progressive bulbar palsy. In primary lateral sclerosis there is exclusively upper motor neurone involvement, and progressive muscular atrophy involves only the lower motor neurones. Each of these conditions is a form of amyotrophic lateral sclerosis as, at necropsy, there is usually evidence of abnormalities of both upper and lower motor neurones. The condition usually spares sensation, eye movements, and sphincter function but a frontotemporal dementia may rarely coexist. The course of MND is usually rapidly progressive, impairment of mobility is common, and many patients have swallowing difficulties.

\section{INCIDENCE AND PROGNOSIS}

The annual incidence is between 1.5 and 2/100 000 and males are more commonly affected than females (1.4:1). The incidence increases with age with a mean age of onset of 63 years. Over $50 \%$ of patients die within three years and $90 \%$ within five years of the first symptom. Early respiratory or bulbar symptoms and increasing age are adverse prognostic indicators. ${ }^{1-3}$

\section{GUIDELINES}

In 1999 the Quality Standards Subcommittee of the American Academy of Neurology presented the first recommendations for the management of amyotrophic lateral sclerosis based on a prescribed review and analysis of the peer reviewed literature. ${ }^{4}$ At the same time a UK MND advisory group, endorsed by the Association of British Neurologists, produced a series of guidelines for the management of MND. ${ }^{5}$ Since that time there have been a number of further review articles and textbooks which have allowed further development of guidelines for best practice. ${ }^{6-13} \mathrm{~A}$ recent study has audited the management of patients in North America after publications of the guidelines illustrating where deficiencies in provision exist. ${ }^{14}$

\section{DIAGNOSIS}

The condition is characterised by the progressive development of combined upper and lower motor neurone signs in a generalised distribution without sensory involvement-however the diagnosis is usually made at an earlier stage when the signs may be restricted. Research criteria for the diagnosis exist, ${ }^{15}{ }^{16}$ but these are rigorous and most patients are considered "possible" or "probable" at the time of diagnosis. Diagnostic difficulty is caused by exclusively upper or lower motor neurone monoparesis or paraparesis without sensory loss, or if there is a particularly long history, young age of onset, or the presence of significant cognitive impairment. Electrophysiology studies are required to confirm the diagnosis and these will show evidence of acute denervation and reinnervation without conduction block. Magnetic resonance imaging of the brain and spinal cord may be necessary to exclude a

Abbreviations: GP, general practitioner; $M N D$, motor neurone disease; $P E G$, percutaneous endoscopic gastrostomy; SOD1, superoxide dismutase 1 
structural lesion and cerebrospinal fluid examination to exclude an infective or inflammatory cause. The initial clinical diagnosis is correct in more than $90 \%$ of cases.

\section{DIFFERENTIAL DIAGNOSIS OF MOTOR NEURONE DISEASE}

The most important differential diagnoses include multifocal motor neuropathy, a condition of lower motor neurone involvement due to multiple conduction block shown electrophysiologically which may be associated with the presence of GMl ganglioside antibodies. This condition may respond to immunomodulatory treatment. Inflammatory polyneuropathies, particularly chronic inflammatory demyelinating neuropathy, may also cause progressive weakness with little or no sensory loss. Other conditions which may be confused with MND include Kennedy's syndrome (X-linked bulbospinal neuronopathy), which is associated with an older age of onset and diffuse, often severe, fasciculations as well as bulbar involvement, variable sensory ataxia, gynaecomastia, and testicular atrophy. It is known to be associated with a specific trinucleotide repeat expansion in the androgen receptor gene (Xq21-22). Adult onset spinal muscular atrophy forms a genetically heterogeneous group of disorders of progressive lower motor neurone wasting and weakness which progress at varying rates and may lead to ventilatory failure. Rarely, metabolic and inflammatory myopathy (polymyositis, inclusion body myositis, thyrotoxicosis) may present with aggressive wasting and weakness mimicking motor neurone disease. Multiple radiculopathy may also present with segmental wasting and weakness mimicking MND.

\section{GENETICS}

A proved cause of MND is mutation of the gene encoding the enzyme copper/zinc superoxide dismutase l (SODl). This accounts for about $2 \%$ of all cases of MND and is present in about $20 \%$ of the approximately $5 \%$ of patients with a family history. To date, over 90 different mutations have been identified. SODl mutation screening is available, but counselling is important before predictive testing can be undertaken. ${ }^{17}$ Mutations in a second gene (alsin) have been described in a small number of patients with autosomal recessive inheritance. ${ }^{18}{ }^{19}$ Linkage has been described in a number of families with the gene still to be identified.

\section{TELLING THE DIAGNOSIS}

The communication of the diagnosis is a major and, potentially devastating, life event, which must be handled with great sensitivity. ${ }^{20}{ }^{21}$ All too often the patients complain that the diagnosis has been given in a hurried, off handed, and inappropriate manner.

The diagnosis should be explained by a senior physician in a quiet and private room, with the patient and their chosen carer(s) with discussion and answering questions. During the consultation the patient should be allowed to dictate the pace and questioning but the neurologist must steer the discussion with sensitivity and care. A second opinion may be offered. The patient should be provided with full access to written information, which is comprehensible. During the consultation it is important to emphasise that a further follow up appointment will be made within two weeks, on-going follow up can be supervised by a single named doctor, and there will be close liaison with the general practitioner (GP) and community services. The patient should be informed about the range of symptomatic and specific treatments. They should also be provided with information about the Motor Neurone Disease Association. The diagnosis and details of the information given to the patient and the management plan must be communicated to the GP without delay.

\section{PRINCIPLES OF MANAGEMENT}

The management of MND involves the coordination of multidisciplinary care with a team which will include the patient's own GP and practice team, therapists, clinical nurse specialists, support and social workers, and the palliative care team. The supervising neurologist or physician should address the full continuum of care for the patient with amyotrophic lateral sclerosis from diagnosis through palliative care to the terminal phase of the disease. Each member of the team will have an individual role. ${ }^{22}$ Physiotherapists may be involved throughout the course of the disease. In the early stages they will instruct on appropriate exercise, advice on gait, compensatory movements, and posture. In later stages passive movements may relieve musculoskeletal pain. Patients and carers will need advice on exercises, stretches, transfers, and positioning. Therapists will provide neck collars designed for patients with MND. Occupational therapists have a crucial role in the assessment and provision of aids for daily living and communication aids including environmental control systems and call systems. They will also coordinate the provision of mobility aids including wheelchairs, sticks, and walking frames. They can advise about adaptations to housing to maintain maximum independence. Social workers and other support and advice workers may counsel about financial benefits and other practical measures as well as provide assistance to patients and families in obtaining the necessary support at home.

The Motor Neurone Disease Association employs a network of regional care advisors throughout England, Wales, and Northern Ireland. ${ }^{23}$ These individuals act as a point of contact for people with MND and their carers, and help to point to the provision of pieces of equipment such as splints and communication aids that may be needed. They also provide a telephone help line and are able to contribute to the support of relatives and carers after the death of the patient.

\section{DISEASE MODIFYING TREATMENT}

Many putative drug treatments for MND have been reported. Such treatments have included agents which might inhibit or prevent cell damage (for example, antiglutamate, antioxidants, antiviral agents, and neurotrophic agents), to enhance neuronal repair (antigangliosides), to inhibit immune mediated damage (immunomodulatory agents), or to enhance neuromuscular function. Apart from riluzole, none of these treatments have been shown to have an effect on the condition.

Intravenous human immunoglobulin is of benefit in patients with inflammatory neuropathic disorders including multifocal motor neuropathy. It may also result in improvement in patients with the clinical syndrome of lower motor neurone involvement in whom there is evidence of motor conduction block, and sometimes in patients where no conduction block is detected. ${ }^{24}$

Riluzole, which inhibits glutamate release, is the only drug which has been shown to increase survival in MND and is licensed in the UK and worldwide, with some exceptions (notably Australia and Canada). ${ }^{25-31}$ Riluzole prolonged survival by three months after 18 months administration with little or no effect on functional deterioration in two clinical trials. Riluzole is usually well tolerated with occasional nausea and fatigue. It is taken as a tablet, as a standard dose of $50 \mathrm{mg}$ twice a day. Blood count and liver function are monitored regularly and the drug is discontinued if liver function tests exceed five times the upper limit of normal. In the UK, riluzole has been recommended for use in the treatment of patients with motor neurone disease by the National Institute for Clinical Excellence. Because of the lack of curative medication, and the progressive nature of the disease, many patients look to other possible treatments. There is no substantial evidence to support therapeutic benefit in patients with motor neurone 
disease. Nevertheless, based on free radical theories of MND pathogenesis, many patients take a range of antioxidant medications, including vitamin $\mathrm{C}$ and vitamin E. Some patients are presently also taking creatine, based on studies in a transgenic SODl mutant mouse model of amyotrophic lateral sclerosis. Some patients also try alternative therapies, including acupuncture, reflexology, chiropracty, and massage. The effects of these approaches are unproved, but they may contribute to the individual's personal feeling of wellbeing.

\section{RESPIRATORY MANAGEMENT}

Respiratory impairment is common in MND and may develop because of respiratory muscle weakness, impaired bulbar function causing aspiration or obstructive sleep apnoea, or defects in central control. Dyspnoea may be due to infection, pulmonary embolus, or airway obstruction from mucus plug or inhaled pharyngeal contents. ${ }^{31}$ Prompt use of antibiotics should be supplemented with physiotherapy. Annual influenza vaccination should be undertaken.

Nocturnal hypoventilation may present as daytime hypersomnolence, lethargy, morning headaches, poor concentration, depression, anxiety, and irritability while obstructive sleep apnoea is characterised by snoring and restless sleep with abnormal movements.

Forced vital capacity reflects respiratory muscle strength, and serial measurements may be useful in predicting the onset of respiratory failure in MND. ${ }^{32-36}$ Some protocols in the USA recommend initiating non-invasive ventilation when forced vital capacity is less than $50 \%$ of predicted. Other markers of impending respiratory failure include maximal inspiratory and expiratory mouth pressures and maximum sniff nasal pressure. ${ }^{32}$ Polysomnography may detect early signs of respiratory insufficiency during sleep ${ }^{37}{ }^{38}$ and diaphragmatic electromyography and phrenic nerve conduction studies may provide useful additional information. ${ }^{39}$ Whichever method is used, careful and detailed discussion with the patient is paramount.

It has been increasingly recognised that the provision of respiratory support can provide symptomatic relief and increase life expectancy. ${ }^{39-45}$ However these benefits must be balanced against the difficulties of compliance in severely disabled patients, the demands on carers and relatives, the practical problems of administrating ventilatory support, the risk of iatrogenic problems, ${ }^{45}$ increasing dependence on ventilatory suppor $\mathrm{t}^{46}$ causing distressing and unwanted prolongation of life, and difficulties in managing the terminal stages in these patients. ${ }^{47-50}$ While many of these difficulties can be avoided by careful discussion with patients and their carers, many patients delay or wish to avoid decisions about embarking on ventilatory support. Elective ventilatory support is usually administered non-invasively via masks (facial or nasal), mouthpieces or nasal pillows, and initially it is usually used for improving respiratory function during sleep. Non-invasive ventilatory support has advantages as it allows speech, oral feeding, has lower costs, and leads to fewer respiratory infections, ${ }^{51}$ but it may not be desirable in patients with severe bulbar weakness, facial abnormalities, or where aspiration has already occurred. Non-invasive ventilatory support may improve survival in MND, reduce the work of breathing, promote good gas exchange, and improve quality of sleep. This often results in improvement of daytime symptoms such as breathlessness and excessive sleepiness. Some patients may require ventilatory support for increasing periods while awake or even continuously and may choose to undergo tracheostomy. ${ }^{52-54}$ Tracheostomy carries a significant risk of complications and considerable difficulties in domiciliary management. ${ }^{55}$ Pulmonary aspiration may still occur with an uncuffed tube. There remains a concern that tracheostomy may lead to prolonged survival in the face of severe disability.
Respiratory failure should be anticipated in all patients once the diagnosis of MND has been made. Optimal management of patients with MND includes protecting autonomy, giving information in advance of deterioration (particularly with regards to respiratory failure), addressing all aspects of care in a multidisciplinary environment, and discussing regularly any advance directives. ${ }^{17}$ After careful discussion many patients will decide to use non-invasive ventilatory support if their respiratory function deteriorates and is symptomatic. The provision and supervision of respiratory support should be through a specialist centre, with experience in the management of MND.

\section{MANAGEMENT OF BULBAR WEAKNESS}

Bulbar palsy is one of the most distressing features of MND. The resulting weakness of tongue, pharynx, and facial muscles results in the loss of salivary control with slow eating, choking, drooling, dysarthria, and dysphonia. ${ }^{56} 57$ Sialorrhoea is generally managed with anticholinergic agents including atropine or amitriptyline taken orally, hyoscine (scopolamine) transdermally, glycopyrronium bromide subcutaneously, or via gastrostomy. Side effects include confusion and exacerbation of glaucoma, particularly in the elderly. ${ }^{58-60}$ Unilateral parotid gland irradiation and direct injection of botulinum toxin into the parotid gland have also been used. ${ }^{61}{ }^{62}$ Whereas antimuscarinic agents render secretions tenacious and viscid, $\beta$-blockers such as propranolol and metoprolol have been reported to reduce secretions without increasing tenacity. ${ }^{60}$ Other approaches include adequate hydration and mucolytics (carbocistine or mecysteine hydrochloride).

\section{DYSPHAGIA}

The management involves speech and language therapy assessment of swallow and advice on techniques to ease mastication and prevent aspiration.

\section{Enteral feeding}

Patients with dysphagia may have inadequate energy and fluid intake, leading to accelerated weight loss and dehydration..$^{63}$ The initial management of dysphagia in amyotrophic lateral sclerosis includes modification of food and fluid consistencies. The dietitian has an important role in ensuring maximal energy intake in as easily digested form as possible. The presence of laryngeal penetration on videofluoroscopy indicates a high risk for the development of aspiration pneumonia. As dysphagia worsens percutaneous endoscopic gastrostomy (PEG) should be considered as an alternative or supplementary route for nutrition and hydration. The immediate benefits of PEG are adequate nutritional intake, weight stabilisation, and an alternative route for medication. ${ }^{6465}$ People with PEG can continue to swallow liquids and solids. In amyotrophic lateral sclerosis, it is recommended that PEG should be undertaken before the forced vital capacity falls below $50 \%$ of predicted and not in the preterminal phase. Complications of the PEG procedure include transient laryngeal spasm, aspiration pneumonia, localised infection, gastric haemorrhage, failure to place PEG due to technical difficulties, and death due to respiratory arrest. ${ }^{66}$ Gastrostomy is more successful and survival improves if it is undertaken before respiratory function deteriorates. It should be considered early, and adequate assistance be made available to the patients, their carers, and community nursing and dietetic staff. Radiological insertion of gastrostomy tube does not require sedation but is associated with a higher risk of complications.

\section{Communication}

To improve communication the speech therapist may recommend aids, ranging from pointing boards (a list of words) to 
computerised speech synthesisers. When a communication aid is needed it is essential that it is provided promptly.

\section{LIMB DYSFUNCTION}

Musculoskeletal pain is commonly experienced and may be managed at any stage with antispasticity agents, non-steroidal anti-inflammatory agents, and stronger analgesics including opiates. ${ }^{67}$ Skin pressure pain due to immobility may also occur Fasciculations are common but and rarely a distressing feature. They tend to improve with disease progression but the symptoms may be eased by carbamazepine. Cramps usually affect the lower limbs, are usually nocturnal, and often uncomfortable. Quinine sulphate, diazepam, carbamazepine, and phenytoin have been used with variable results. Stiffness may be due to spasticity or muscle or joint contracture. This has been treated by increasing doses of baclofen but tizanidine is now a valuable alternative. Spasticity may compromise mobility but can aid weak legs to support the body.

\section{PSYCHOLOGICAL FACTORS}

Depression and anxiety often follow the diagnosis of MND. Both should be treated appropriately, and not viewed as unavoidable consequences of a progressive disease. The drugs of choice for depression in this context include serotonin reuptake inhibitors, for example fluoxetine. Anxiety may be severe enough to require specific drug therapy. This may be short term treatment with benzodiazepines but amitriptyline can also help. ${ }^{68}$ Aggression and disinhibition may be a feature of cognitive impairment. Phenothiazines may be necessary, and psychiatric support is often helpful.

Emotional lability is usually associated with pseudobulbar palsy. It may be distressing to the patient and his carers. Emotional lability may be eased by amitriptyline or a serotonin reuptake inhibitor such as citalopram, fluoxetine, or paroxetine ${ }^{69-71}$

\section{OTHER SYMPTOMS}

Insomnia is common in MND and may relate to physical discomfort, anxiety, or respiratory compromise. If sleep remains disturbed after relief of pain then sedatives may help. Amitriptyline is preferable to hypnotics, which are most likely to exacerbate respiratory insufficiency. Constipation is treated by dietary advice and ample fluid intake supplemented by Fybogel, lactulose, and co-danthromer.

\section{TERMINAL CARE}

Palliative care should be introduced before the terminal stages of MND. ${ }^{72}$ Home care teams and day centres may offer respite care, with a parallel set of therapists and support staff complementing those provided elsewhere. There must be close liaison with the GP, community health care, and hospice teams. The terminal stages of the disease should be managed in close liaison with palliative care physicians. ${ }^{72-75}$

Terminal care often involves alleviating psychological distress and the symptoms of bulbar weakness and respiratory failure. Patients may experience a frightening sensation of choking due to episodes of laryngospasm. Benzodiazepines and agents to dry secretions may be helpful but laryngospasm usually resolves spontaneously. Oral, subcutaneous, or intravenous morphine may be indicated to relieve dyspnoea, anxiety, pain, hunger, or other distress. The effectiveness of sedatives such as diazepam, midazolam, or chlorpromazine in reducing anxiety in the terminal stages outweighs any depressive action of the drugs on respiratory function. ${ }^{76-83}$

The "Breathing Space Kit", provided by the Motor Neurone Disease Association in the UK, contains medication which can be used by the carer, nurse, or GP for the emergency treatment of acute episode of respiratory distress which often occurs in the terminal stages. These include diazepam, diamorphine, chlorpromazine, and hyoscine.
Key references from the last five years

- Miller RG, Rosenberg JA, Gelinas DF, et al. Practice parameters. The care of the patient with amyotrophic lateral sclerosis (an evidence-based review): report of the Quality Standards Subcommittee of the American Academy of Neurology: ALS Practice Parameters Task Force. Neurology 1999;52:1311-23.

- Exerpta Medica MND Advisory Group. Guidelines for the management of motor neurone disease (MND). Endorsed by the Council of the Association of Neurologists, 1999 (http://www.theabn.org/downloads/mnddoc.pdp).

- Miller RG, Mitchell JD, Moore DH. Riluzole for amyotrophic lateral sclerosis / motor neurone disease (Protocol for a Cochrane review). The Cochrane Library, Issue 2, 2002. Oxford: Update Software.

- Orrell RW, Figlewicz DA. Clinical implications of the genetics of ALS and other motor neuron diseases. Nevology 2001;57:9-17

- Bradley WG, Anderson F, Bromberg M, et al. Current management of ALS. Neurology 2001;57:500-4.

\section{Useful web sites}

- www.wfnals.org

World Federation of Neurology, Amyotrophic Lateral Sclerosis site.

- www.mndassociation.org

Motor Neurone Disease Association (England, Wales and Northern Ireland).

- www.alsmndalliance.org

International Alliance of ALS/MND Associations

- www.cochrane.org

The Cochrane collaboration (includes report on riluzole)

- www.theabn.org/downloads/mnddoc.pdp

Guidelines for the management of motor neurone disease, endorsed by the Association of British Neurologists.

- www.alsa.org

ALS Association (USA).

- www.scotmnd.org.uk

Scottish Motor Neurone Disease Association.

- www.nice.org.uk

National Institute for Clinical Excellence-includes review and recommendations for the use of riluzole.

\section{CARERS}

After the death of an MND sufferer the family and carers will require bereavement support. ${ }^{84}{ }^{85}$ This may be provided by the palliative care team but continuing domiciliary support may also be necessary.

\section{CONCLUSION}

The development of clinical guidelines for the management of MND has provided a valuable stimulus to address and improve the present provision of service for patients with MND in the UK. However, as Bradley et al have illustrated in the USA, ${ }^{6}$ there remains an overwhelming need for better access to diagnostic, rehabilitation, technical and palliative care for these patients and their carers.

\section{QUESTIONS AND ANSWERS}

\section{What is motor neurone disease?}

Motor neurone disease is a neurodegenerative disease affecting upper and lower motor neurones. In many countries this is referred to as amyotrophic lateral sclerosis.

\section{What is the cause of motor neurone disease?}

The cause is largely unknown. Approximately $2 \%$ of patients have mutations in the SODl gene, and most of these patients 
show autosomal dominant inheritance. Genetic counselling may be considered in patients with a family history of motor neurone disease (around 5\%-10\% of all patients).

\section{What is the youngest age a patient can present with motor neurone disease?}

Typically patients present in mid and late life but patients may develop the condition at any age, including the 20 s and 30 s. Rarely juvenile forms may occur.

\section{Is there a curative treatment for motor neurone disease?}

There is no treatment that will halt or reverse the progression of the disease. Riluzole is the only licensed medication for slowing the progression of the disease.

\section{How may respiratory support benefit patients with motor neurone disease?}

Non-invasive ventilation may provide amelioration of symptoms related to respiratory insufficiency, without causing significant extension of survival. More active and invasive respiratory support may extend survival in the face of severe disability.

\section{What intervention has most significantly altered quality of life and survival of patients with motor neurone disease in recent years?}

The active management of nutrition, including consideration of the early placement of PEG, has probably had the largest impact on the quality of life and survival by minimising cachexia, starvation, and aspiration.

\section{What other conditions should be considered when making the diagnosis of motor neurone disease?}

A wide range of neurological conditions may be confused with the initial presentation of motor neurone disease. With time the diagnosis usually becomes clear. Important treatable conditions to consider in the differential diagnoses include multifocal motor neuropathy, and other inflammatory neuropathies, which may respond to intravenous human immunoglobulin. Inflammatory myopathies, including polymyositis, may respond to steroid treatment. Also surgically treatable conditions in the brain, spinal cord, or peripheral nerves should be considered. Other rarer hereditary neuropathies, including Kennedy's disease, may have important genetic implications for the family.

\section{Authors' affiliations}

R S Howard, National Hospital for Neurology and Neurosurgery, London

R W Orrell, Department of Clinical Neurosciences, Royal Free and University College Medical School, London

\section{REFERENCES}

1 Ringel SP, Murphy JR, Alderson MK, et al. The natural history of amyotrophic lateral sclerosis. Neurology 1993;43:1316-22.

2 Haverkamp LJ, Appel V, Appel SH. Natural history of amyotrophic lateral sclerosis in a database population. Validation of a scoring system and a model for survival prediction. Brain 1995;118:707-19.

3 Stambler N, Charatan M, Cedarbaum JM. Prognostic indicators of survival in ALS. ALS CNTF Treatment Study Group. Neurology 1998;50:66-72.

4 Miller RG, Rosenberg JA, Gelinas DF, et al. Practice parameters. The care of the patient with amyotrophic lateral sclerosis (an evidence-based review): report of the Quality Standards Subcommittee of the American Academy of Neurology: ALS Practice Parameters Task Force. Neurology 1999.52:1311-23.

5 Exerpta Medica MND Advisory Group. Guidelines for the management of motor neurone disease (MND). Endorsed by the Council of the Association of Neurologists, 1999 (http://www.theabn.org/ downloads/mnddoc.pdp).

6 Bradley WG, Anderson F, Bromberg M, et al. Current management of ALS. Neurology 2001;57:500-4.

7 Borasio GD. Meditation and ALS. In: Mitsumoto H, Munsat T, eds. Amyotrophic lateral sclerosis: a comprehensive guide to management. New York: Demos Medical Publishers, 2001: 271-6.
8 Gelinas DF, Miller RG. A treatable disease: a guide to the management of amyotrophic lateral sclerosis, In: Brown RH Jr, Meininger V, Swash M, eds. Amyotrophic lateral sclerosis. London: Martin Dunitz, 2000: 405-21.

9 Oliver D. Palliative care for motor neurone disease. Practical Neurology 2002;2:68-79.

10 Miller RG, Mitchell JD, Moore DH. Riluzole for amyotrophic lateral sclerosis/motor neurone disease (Protocol for a Cochrane review). The Cochrane Library, Issue 2, 2002. Oxford: Update Software.

11 Hardiman 0 . Symptomatic treatment of respiratory and nutritional failure in amyotrophic lateral sclerosis. I Neurol 2000;247:245-51.

12 Borasio GD, Volz R, Miller RG. Palliative care in amyotrophic lateral sclerosis. Neurol Clin 2001;19:829-48.

13 Borasio GD, Miller RG. Clinical characteristics and management of ALS Semin Neurol 2001;21:155-66.

14 Bradley WG, Anderson F, Bromberg M, et al. Current management of ALS-comparison of the ALS CARE database and the AAN practice parameter. Neurology 2001;57:500-4.

15 Subcommittee on Motor Neuron Diseases/Amyotrophic Lateral Sclerosis of the World Federation of Neurology Research Group on Neuromuscular Diseases, El Escorial "Clinical Limits of Amyotrophic Lateral Sclerosis" Workshop Contributors. El Escorial World Federation of Neurology criteria for the diagnosis of amyotrophic lateral sclerosis. J Neurol Sci 1994:124(suppll:96-107.

16 World Federation of Neurology Research Group on Motor Neuron Disease. Revised criteria for the diagnosis of Amyotrophic Lateral Sclerosis, 1998 (http://wfnals.org/Articles/elescorial 1998.htm).

17 Orrell RW, Figlewicz DA. Clinical implications of the genetics of ALS and other motor neuron diseases. Nevology 2001;57:9-17.

18 Yang Y, Hentati A, Deng HX, et al. The gene encoding alsin, a protein with three guanine nucleotide exchange factor domains, is mutated in a form of recessive amyotrophic lateral sclerosis. Nat Genet 2001;29: 160-5.

19 Hadano S, Hand CK, Osuga $\mathrm{H}$, et al. A gene encoding a putative GTPase regulator is mutated in familial amyotrophic lateral sclerosis. Nat Genet 2001;29:166-73

20 Borasio GD, Sloan R, Pongratz DE. Breaking the news in amyotrophic lateral sclerosis. J Neurol Sci 1998;160(suppl 1):S127-33.

21 Meininger V. Breaking bad news in amyotrophic lateral sclerosis. Palliat Med 1993:7:37-40

22 Molloy I. Rehabilitation. In: Oliver D, Borasio GD Walsh D, eds. Palliative care in amyotrophic lateral sclerosis. Oxford: Oxford University Press, 2000: 135-42

23 Holmes T. MND Association of England Wales and Northern Ireland. In: Oliver D, Borasio GD, Walsh D, eds. Palliative care in amyotrophic lateral sclerosis. Oxford: Oxford University Press, 2000: 143-7.

24 Ellis CM, Leary S, Payan J, et al. Use of human intravenousimmunoglobulin in lower motor neuron syndromes. J Neurol Neurosurg Psychiatry 1999;67:15-19.

25 Bensimon G, Lacomblez L, Meininger V, et al. A controlled trial of riluzole in amyotrophic lateral sclerosis. N Engl J Med 1994;330:585-91

26 Demaerschalk BM, Strong M. Amyotrophic lateral sclerosis. Current Treatment Options in Neurology 2000:2:13-22.

27 Lacomblez L, Bensimon G, Leigh PN, et al. Dose ranging study of riluzole in amyotrophic lateral sclerosis. Lancet 1996;347:1425-31.

28 Meininger V, Zeisser P, Munsat T. An analysis of extended survival in patients with amyotrophic lateral sclerosis treated with riluzole. Arch Neurol 1998;55:526-8.

29 Quality Standards Subcommittee of the American Academy of Neurology. Practice advisory on the treatment of amyotrophic lateral Neurology. Practice advisory on the treatment of
sclerosis with riluzole. Neurology 1997;49:657-9.

30 Swash M. Pharmacoeconomics and motor neuron disease. J Neurol Neurosurg Psychiatry 2000;68:401-3

31 Howard RS, Wiles CM, Loh L. Respiratory complications and their management in motor neurone disease. Brain 1989;112:1155-70.

32 Lyall RA, Donaldson N, Polkey Ml, et al. Respiratory muscle strength and ventilatory failure in amyotrophic lateral sclerosis. Brain 2001;124:2000-13.

33 Hopkins LC, Tatarian GT, Pianta TF. Management of ALS: respiratory care. Neurology 1996;47(suppl 2): 123-5

34 Melo J, Homma A, Iturriaga $\mathrm{E}$, et al. Pulmonary evaluation and prevalence of non- invasive ventilation in patients with amyotrophic lateral sclerosis: a multicenter survey and proposal of a pulmonary protocol. J Neurol Sci 1999:169:114-17.

35 Brooks BR. Natural history of ALS: symptoms, strength, pulmonary function, and disability. Neurology 1996;47:S71-82.

36 Schiffman PL, Belsh JM. Pulmonary function at diagnosis of amyotrophic lateral sclerosis. Rate of deterioration. Chest 1993;103:508-13.

37 David WS, Bundlie SR, Mahdavi Z. Polysomnographic studies in amyotrophic lateral sclerosis. J Neurol Sci 1997;152(suppl):S29-35.

38 Kimura K, Tachibana N, Kimura J, et al. Sleep-disordered breathing at an early stage of amyotrophic lateral sclerosis. J Neurol Sci 1999: 164:37-43

39 Evangelista T, de Carvalho M, Pinto A, et al. Phrenic nerve conduction in amyotrophic lateral sclerosis. J Neurol Sci 1995;129(suppl):35-7.

40 Aboussouan LS, Khan SU, Meeker DP, et al. Effect of noninvasive positive-pressure ventilation on survival in amyotrophic lateral sclerosis. Ann Intern Med 1997; 127:450-3.

41 Cazzolli PA, Oppenheimer EA. Home mechanical ventilation for amyotrophic lateral sclerosis: nasal compared to tracheostomy-intermittent positive pressure ventilation. J Neurol Sci 1996; 139(suppl): 123-8 
42 Hillberg RE, Johnson DC. Non-invasive ventilation. N Engl J Med 1997:337:1746-52.

43 Pinto AC, Evangelista T, Carvalho $M$, et al. Respiratory assistance with a non-invasive ventilator (Bipap) in MND/ALS patients: survival rates in a non-invasive ventilator (Bipap) in MND/ALS patient
controlled trial. J Neurol Sci 1995:129:S19-26.

44 Kleopa AK, Sherman M, Neal B, et al. Bipap improves survival and rate of pulmonary function decline in patients with ALS. J Neurol Sci 1999; 164:82-8.

45 Carrey Z, Gottfried SB, Levy RD. Ventilatory muscle support in respiratory failure with nasal positive pressure ventilation. Chest 1990:97:150-8.

46 Gelinas DF, O'Connor P, Miller RG. Quality of life for ventilator-dependent ALS patients and their caregivers. J Neurol Sci 1998;160(suppl 1):S134-6.

47 Bradley MD, Orrell RW, Clarke J, et al. Outcome of ventilatory support for acute respiratory failure in motor neurone disease. J Neurol Neurosurg Psychiatry 2002 (in press).

48 Hayashi H, Kato S, Kawada A. Amyotrophic lateral sclerosis patients living beyond respiratory failure. J Neurol Sci 1991;105:73-8.

49 Hayashi H. Ventilatory support: Japanese experience. J Neurol Sci 1997; 152(suppl 1):97-100.

50 Hayashi $\mathbf{H}$, Kato S. Total manifestations of amyotrophic lateral sclerosis. ALS in the totally locked-in state. J Neurol Sci 1989;93:19-35.

51 Hill NS. Noninvasive ventilation positive pressure ventilation in neuromuscular disease. Enough is enough. Chest 1995;105:337-8.

52 Moss AH, Oppenheimer EA, Casey P, et al. Patients with amyotrophic lateral sclerosis receiving long-term mechanical ventilation: advance care planning and outcomes. Chest 1996;1 10:249-55.

53 Moss AH, Casey P, Stocking CB, et al. Home ventilation for amyotrophic lateral sclerosis patients: outcomes, costs, and patient, family and physician attitudes. Neurology 1993;43:438-43.

54 Oppenheimer EA. Decision-making in the respiratory care of amyotrophic lateral sclerosis: should home mechanical ventilation be used? Palliat Med 1993;5(suppl 2):49-64.

55 Bach JR. Amyotrophic lateral sclerosis. Communication status and survival with ventilatory support. Am J Phys Med Rehabil 1993:72:343-9.

56 Hadiikoutis S, Eccles R, Wiles CM. Coughing and choking in motor neurone disease. J Neurol Neurosurg Psychiatry 2000;68:601-4.

57 Leighton SEJ, Burton M, Lund WS, et al. Swallowing in motor neuron disease. J R Soc Med 1994;87:801-5

58 Blasco PA, Stansbury JCK. Glycopyrrolate treatment of chronic drooling. Arch Pediatr Adolesc Med 1996;150:932-5.

59 Stern LM. Preliminary study of glycopyrrolate in the management of drooling. J Paediatr Child Health 1997;33:52-4.

60 Newall AR, Orser $R$, Hunt $M$. The control of oral secretions in bulbar ALS/MND. J Neurol Sci 1996;139(suppl):43-4

61 Robinson ACR, Khoury GG, Robinson PM. Role of irradiation in the suppression of parotid secretions. J Laryngol Otol 1989;103:594-5.

62 Giess R, Naumann M, Werner E, et al. Injections of botulinum toxin A into the salivary glands improve sialorrhoea in amyotrophic lateral sclerosis. J Neurol Neurosurg Psychiatry 2000;69:121-3.

63 Kasarskis EJ, Berryman S, Vanderleest JG, et al. The nutritional status of patients with amyotrophic lateral sclerosis: relation to the proximity of death. Am J Clin Nutr 1996:63:130-7.
64 Mazzini L, Corra T, Zaccala M, et al. Percutaneous endoscopic gastrostomy and enteral nutrition in amyotrophic lateral sclerosis. Neurology 1995;242:695-8.

65 Mathus-Vliegen LMH, Louwerse LS, Merkus MP, et al. Percutaneous endoscopic gastrostomy in patients with amyotrophic lateral sclerosis and impaired pulmonary function. Gastrointest Endosc 1994;40:463-9.

66 Light VL, Slezak FA, Porter JA, et al. Predictive factors for early mortality after percutaneous endoscopic gastrostomy. Gastrointest Endosc 1995:42:330-5.

67 Newrick PG, Langton-Hewer R. Pain in motor neuron disease. J Neurol Neurosurg Psychiatry 1985;48:838-40.

68 Caroscio JT, Cohen JA, Gudesblatt M. Amitriptyline in amyotrophic lateral sclerosis. N Engl J Med 1985;313:1478

69 Iannaccone S, Ferini-Strambi L. Pharmacologic treatment of emotional lability. Clin Neuropharmacol 1996:19:532-5.

70 Schiffer RB, Cash J, Herndon RM. Treatment of emotional lability with low-dosage tricyclic antidepressants. Psychosomatics 1983;24:1094-6.

71 Schiffer RB, Herndon RM, Rudick RA. Treatment of pathologic laughing and weeping with amitriptyline. N Engl J Med 1985;312:1480-2.

72 Borasio GD, Voltz R. Advance directives. In: Oliver D, Borasio GD, Walsh D, eds. Palliative care in amyotrophic lateral sclerosis. Oxford: Oxford University Press, 2000: 36-41.

73 Albert SM, Murphy PL, Del Bene ML, et al. Prospective study of palliative care in ALS: choice, timing and outcomes. J Neurol Sci 1999; 169:108-13.

74 Albert SM, Murphy PL, Del Bene ML, et al. A study of preferences and actual treatment choices in ALS. Neurology 1999:53:278-83.

75 O'Brien T, Kelly M. Sunders C. Motor neuron disease: a hospice perspective. BM 1992;304:471-3.

76 Voltz R, Borasio G. Palliative therapy in the terminal stage of neurological disease. Neurology 1997;244(suppl 4):S2-10.

77 Doyle D, O'Connell S. Breaking bad news: starting palliative care. J $R$ Soc Med 1996:89:590-1.

78 Oliver D, Borasio GD, Walsh D, eds. Palliative care in amyotrophic lateral sclerosis (motor neurone disease). Oxford: Oxford University Press, 2000.

79 Oliver D, Webb S. The involvement of specialist palliative care in the care of people with motor neuron disease. Palliat Med 2000;14:427-8.

80 Oliver $\mathbf{D}$. Opioid medication in the palliative care of motor neurone disease. Palliat Med 1998;12:113-5.

81 Sykes N. End-of-life care in ALS. In: Oliver D, Borasio GD, Walsh D, eds. Palliative care in amyotrophic lateral sclerosis. Oxford: Oxford University Press, 2000: 159-68

82 Borasio GD, Voltz R. Discontinuation of life support in patients with amyotrophic lateral sclerosis. J Neurol 1998;245:717-22.

83 Neudert C, Oliver D, Wasner M, et al. The course of the terminal phase in patients with amyotrophic lateral sclerosis. J Neurol 2001;248:612-16

84 Goldstein LH, Adamson M, Jeffrey L, et al The psychological impact of MND on patients and carers. J Neurol Sci 1998;160(suppl 1):S1 14-21.

85 Martin J, Turnbull J. Lasting impact, and ongoing needs, in families months to years after death from ALS. Amyotr Lat Scler 2000;1 (supp 3):514-15. 